\title{
Patterns of fatal machine rollovers in Canadian agriculture
}

\author{
J.M. DeGroot, MSc (1); C. Isaacs, MSc (1); W. Pickett, PhD (1,2); R.J. Brison, MPH (1,2,3)
}

\begin{abstract}
Introduction: Our objectives were to examine the activities and circumstances associated with agricultural machine-related rollover fatalities.

Methods: We identified agricultural machine rollover fatalities recorded by the Canadian Agricultural Injury Surveillance Program (CAISP) in 1990-2005. We determined sideways and backwards rollovers by year, age and sex of the victims, agricultural season, machine type, and the activity, circumstances and location of the injury event.
\end{abstract}

Results: The annual rate of rollover fatalities in Canada was 9.1 per 100000 farm operations. Rollover fatalities decreased to $30 \%$ of baseline over the 16-year study period ( $p=.004$ ). Fatal rollovers most often occurred among men aged 50-69 years and 60-79 years for sideways and backwards rollovers, respectively.

Discussion: Sideways rollovers occur when driving across an incline or at the edge of a ditch bordering a roadway or field. Backwards rollovers occur when driving up an incline, towing or extracting stuck machines, pulling stumps or trees, and towing implements or logs. Primary prevention programs for rollover injuries should target these identified patterns of injury.

Keywords: agricultural machine rollover, agricultural injuries, injury prevention, mortality, rollover protection structures, injury surveillance

\section{Introduction}

Agriculture is one of the most dangerous industries in Canada, with estimated annual population fatality rates between 14.6 and 25.6 per $100000 .^{1}$ It is similarly hazardous in other developed countries., ${ }^{2,3}$ In Canada, agricultural-related machine rollovers-when a vehicle or machine turns over either onto its side or backwards-account for approximately 40 hospitalizations (2.4\% of agriculture-related hospitalized injuries) and 21 fatalities per year $(20 \%$ of agriculture-related fatal injuries). ${ }^{1,4}$ Rollover events develop rapidly leaving little or no time for evasive action; tractors can tip backwards to the point of no return in 0.75 seconds. ${ }^{5}$

There is ample evidence to support the efficacy of rollover protection structures (ROPS) as a secondary prevention strategy in reducing injury in rollover events.-8 (Secondary prevention is defined as any strategy that limits the severity of an injury during the occurrence of an injury event such as a rollover.) $)^{9}$ There are less data available to inform primary prevention strategies that might decrease the occurrence of rollover events. (Primary prevention is defined as any strategy that might prevent the occurrence of the injury event in the first place. $)^{9}$

A number of studies have examined rollovers while exploring a spectrum of agricultural workplace injuries. ${ }^{1-4}$ However, a recent search of the biomedical literature did not identify any studies that describe common patterns of occurrence for rollover injuries. Knowing the circumstances of injury events and the people involved can inform primary prevention methods for rollover events and perhaps better target secondary strategies such as ROPS installation. Identifying the most hazardous situations and those people at highest risk could assist in targeting prevention messages.

The objectives of this study were to use data from a national agricultural injury surveillance program in Canada to examine the activities and circumstances associated with fatal agricultural-related rollover injuries and to describe who sustained these injuries.

\section{Methods}

\section{Study population and data collection}

Ethics approval was provided by Queen's University Health Sciences Research Ethics Board.

The study population included all people who died as a result of a vehicle or machine rollover on a Canadian farm or ranch between January 1, 1990, and December 31, 2005. Cases were identified by the Canadian Agricultural Injury Surveillance Program (CAISP). ${ }^{1}$ Briefly, CAISP identified accidental

Author references

1. Clinical Research Centre, Kingston General Hospital, Kingston, Ontario, Canada

2. Department of Community Health and Epidemiology, Queen's University, Kingston, Ontario, Canada

3. Department of Emergency Medicine, Queen's University, Kingston, Ontario, Canada

Correspondence: Robert Brison, Kingston General Hospital, 76 Stuart Street, Kingston ON K7L 2V7. Tel.: (613) 548-2389; Fax: (613) 548-1381; Email: brisonr@kgh.kari.net 
agriculture-related injury fatalities in databases maintained by offices of provincial coroners or chief medical examiners in the ten Canadian provinces. Each coroner's file is abstracted on-site by CAISP provincial collaborators using a standardized template. ${ }^{1}$ Fatal rollover information was not available from the province of Quebec for 2004 and 2005. CAISP also identifies hospitalized cases of agricultural injury; ${ }^{4}$ however, as the focus of our analysis was on patterns associated with fatal injuries only, these data were not considered here.

\section{Injury definition}

We reviewed documentation on fatal agriculture-related injuries and coded those caused by rollovers. We defined a backwards rollover as one where the vehicle or machine turns over backwards with its front tires rotating around its rear axle by $90^{\circ}$ to $180^{\circ}$ and a sideways rollover as one where a vehicle or machine turns onto its side. Incidents that did not have sufficient documentation to determine whether the rollover was backwards or sideways were deemed unspecified.

\section{Data analysis}

We counted the number of backwards and sideways rollovers described in CAISP for the time period 1990 to 2005. We profiled sideways and backwards rollovers by age and sex of the victims, type of machine, agricultural season, location of the injury event, type of activity prior to rollover, and most probable cause of rollover. Overall and age-specific annual rates of fatal injury were calculated per 100000 farms and then per 100000 people using population estimates from the 1996 Canada Census of Agriculture as the denominator. ${ }^{10}$ All analyses were performed using SAS software (version 9.2, SAS Institute Inc., Cary, NC, United States).

\section{Results}

\section{Number of rollovers}

Of the 1766 agriculture-related fatalities identified between 1990 and 2005, 360 (20.4\%) were due to rollovers. Of these, 221 (61.4\%) were sideways rollovers, 107 (29.7\%) were backwards rollovers, and 32 (8.9\%) were unspecified (Table 1). The overall number of rollovers decreased significantly from a high of 31 in 1990 to a low of 9 in 2005

TABLE 1

Number of fatal agriculture-related rollovers by type of rollover, personal characteristics of the victim and rollover circumstance

\begin{tabular}{|c|c|c|}
\hline & \multicolumn{2}{|c|}{$\begin{array}{c}\text { Number of rollovers, } \\
n\end{array}$} \\
\hline & $\begin{array}{l}\text { Sideways } \\
(\mathbf{n}=221)\end{array}$ & $\begin{array}{c}\text { Backwards } \\
(\mathrm{n}=107)\end{array}$ \\
\hline \multicolumn{3}{|l|}{ Age of victim, years } \\
\hline $0-9$ & 4 & 3 \\
\hline $10-19$ & 29 & 5 \\
\hline $20-29$ & 13 & 10 \\
\hline $30-39$ & 21 & 7 \\
\hline $40-49$ & 28 & 15 \\
\hline $50-59$ & 35 & 15 \\
\hline $60-69$ & 46 & 25 \\
\hline 70-79 & 28 & 22 \\
\hline $80+$ & 17 & 5 \\
\hline \multicolumn{3}{|l|}{ Sex of victim } \\
\hline Male & 207 & 103 \\
\hline Female & 14 & 4 \\
\hline \multicolumn{3}{|l|}{ Agricultural season } \\
\hline Harvest, July-Oct & 126 & 47 \\
\hline Planting, April-June & 46 & 39 \\
\hline Winter, Nov-March & 49 & 19 \\
\hline Unknown & 0 & 2 \\
\hline \multicolumn{3}{|l|}{ Machine type } \\
\hline Tractor & 189 & 97 \\
\hline Off-road vehicle & 11 & 8 \\
\hline Construction equipment & 6 & 2 \\
\hline Motor vehicle & 6 & 0 \\
\hline Other & 9 & 0 \\
\hline \multicolumn{3}{|l|}{ Location of injury event } \\
\hline Field & 44 & 44 \\
\hline Public road & 71 & 6 \\
\hline Farm road & 39 & 10 \\
\hline Woodlot & 14 & 32 \\
\hline Water source & 24 & 3 \\
\hline Farmyard & 7 & 4 \\
\hline Driveway & 10 & 0 \\
\hline Farm building & 5 & 3 \\
\hline Other & 4 & 3 \\
\hline Unknown & 3 & 2 \\
\hline
\end{tabular}

Notes: Bolding highlights the most prevalent patterns of risk.

( $p=.004)$, with considerable variability in the annual occurrence of both sideways and backwards rollovers. (Note: The observed decline should be interpreted cautiously due to the lack of fatality records from Quebec for 2004-2005). Though counts of rollover events varied over the study period, a descending trend in numbers of sideways rollovers was statistically significant ( $p=.01$ ) while a descending trend in numbers of backwards rollovers was less clear $(p=.08)$ (Figure 1$)$. 
FIGURE 1

Number of fatal agriculture-related sideways and backwards rollovers by year with trend lines

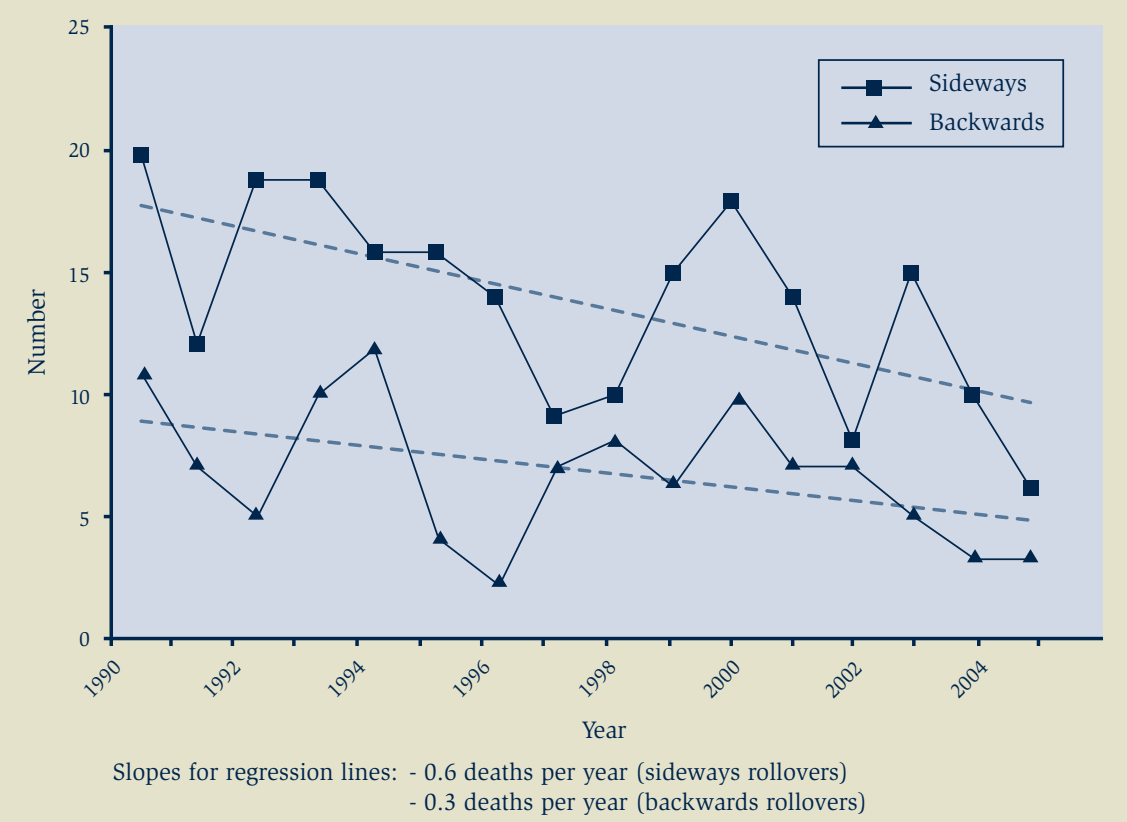

\section{Injury circumstances}

That older age groups experienced large number of rollover injury events is consistent with the known demographic distribution of farmers in Canada. ${ }^{10}$ The highest number of fatal sideways rollovers occurred in people aged 50 to 69 years, and the highest number of backwards rollovers in those aged 60 to 79 years (Table 1). Fatal rollovers occurred most often among men and boys, with the majority occurring during the harvest season, and on tractors, irrespective of the type of rollover. The next most common machine type for both sideways and backwards rollovers was the off-road vehicle ( $n=19)$; of these, $8(42.1 \%)$ were reported for children aged 16 years and less. Available injury narratives suggest that almost all of these children were engaged in recreational rather than work-related activities at the time of the accident. Sideways rollovers were most likely to occur on fields or public roads while backwards rollovers were most likely to occur in a field or a woodlot (woods, forest or orchard).

\section{Rates of fatal rollover injuries}

We estimated annual rates of fatal rollover injury per 100000 farm operations at 9.1 for total fatal rollovers, 5.6 for sideways rollovers and 2.7 for backwards rollovers. Annual rates of fatal rollover injury per 100000 farm population were 2.4 for total fatal rollovers, 1.6 for sideways rollovers and 0.8 for backwards rollovers. Annual age-specific rates of rollover injury generally increased with age for both sideways rollovers (minimum 0.2 per 100000 for ages 0-9; maximum 13.7 per 100000 for ages $80+$ ) and backwards rollovers (minimum 0.2 per 100000 for ages $0-9$; maximum 4.5 per 100000 for ages 70-79).

\section{Activities and contributing factors}

The most common activities contributing to sideways rollovers were transportation (particularly on public roadways) and field work. For backwards rollovers, the most common activities were forestry, field work and towing or extraction (Table 2). Factors contributing to the occurrence of sideways rollovers were (1) driving too close to the edge of a ditch or an embankment and (2) driving on an incline. Most backwards rollovers were associated with (1) attempting to free stuck machines with a tractor or towing machines; (2) driving on an incline or dragging logs or implements; and (3) pulling stumps or trees.

\section{Discussion}

Our study describes a number of clear patterns of injury associated with fatal rollover injuries on Canadian farms. We found that men are much more frequently involved in a fatal rollover. Locker et al. reported an age-standardized rate ratio for males to females of 11.8 to 1 for rollovers that resulted in hospitalization or death. ${ }^{11}$ Similar patterns are found in other types of agriculture-related injuries. ${ }^{2,11-12}$ Adults aged 50 to 79 years account for the highest number of sideways and backwards rollover fatalities. This is consistent with US-based reports by Myers et al. who found that the risk of rollover fatality increases with age, with people aged 75 years and older having approximately 6.5 times the rate of death compared 
TABLE 2

Activity and factors contributing to fatal agriculture-related rollover events

\begin{tabular}{|c|c|c|}
\hline & \multicolumn{2}{|c|}{ Number of rollovers } \\
\hline & $\begin{array}{l}\text { Sideways } \\
(\mathrm{n}=221)\end{array}$ & $\begin{array}{c}\text { Backwards } \\
(n=107)\end{array}$ \\
\hline \multicolumn{3}{|l|}{ Activity at time of event } \\
\hline Transportation & 123 & 8 \\
\hline Field work & 38 & 23 \\
\hline Forestry & 14 & 39 \\
\hline Towing (extraction) & 7 & 23 \\
\hline Working in farm yard & 12 & 9 \\
\hline Mowing & 12 & 0 \\
\hline Recreation & 5 & 2 \\
\hline Road Maintenance & 4 & 1 \\
\hline Unknown & 6 & 2 \\
\hline \multicolumn{3}{|l|}{ Factors contributing to rollover event } \\
\hline Driving too close to edge of a ditch or embankment & 104 & 12 \\
\hline Driving on an incline & 62 & 19 \\
\hline Towing (extraction) & 7 & 23 \\
\hline Dragging logs/implements & 4 & 19 \\
\hline Pulling stumps/trees & 0 & 14 \\
\hline Rough terrain & 5 & 7 \\
\hline Fall from ramp & 7 & 1 \\
\hline Collision with object & 6 & 2 \\
\hline Cornering & 6 & 1 \\
\hline Carrying heavy load in bucket & 6 & 1 \\
\hline Pulling heavy machine/trailer & 4 & 3 \\
\hline Tractor arms/bucket caught in ground & 2 & 0 \\
\hline Unknown & 8 & 5 \\
\hline
\end{tabular}

Notes: Bolding highlights the patterns of risk that are most prevalent.

to people aged 25 to 34 years. ${ }^{13}$ The tendency for farmers to work past the normal age of retirement is recognized, and is associated with an increased risk for injury. ${ }^{14-17}$ Because tractors are built to last, many older operators use tractors that were made before manufacturers routinely installed ROPS, thereby increasing their likelihood of fatality during a rollover. ${ }^{18-21}$

The most common cause of sideways rollovers is as a result of driving too close to the edge of a steep slope, usually a ditch by a public roadway or a field, and this usually occurs during transportation or field work. Rissanen and Taattola found that another common cause is driving across an incline in such a way that the machine goes beyond its stability baseline and overturns. ${ }^{12}$ Driving up an incline is also a common cause.
Backwards rollovers usually occur in circumstances that use the same mechanism: towing or extraction of machines, dragging logs or implements, and pulling stumps or trees in a field or woodlot. Rissanen and Taattola reported that backwards rollovers generally occur when towing another tractor, ${ }^{12}$ while our data suggest that towing, dragging or pulling any object is the more likely cause. Improper hitching, where the hitch is mounted above the level of the rear axle, is a frequent cause of backwards rollovers; approximately $60 \%$ of the 16 reported backwards rollovers on tractors in New York from 1991 to 1995 involved improper hitching.?

Reports on rollovers often discuss the use of ROPS on tractors as a means of reducing the severity of injury. Because of the extremely low probability of death due to rollover on ROPS-equipped tractors, ${ }^{6-8}$ it is likely that very few of the tractors in our study $(88 \%$ of all fatal agriculture-related rollover injuries in Canada occurred on tractors) used ROPS as a secondary prevention strategy. The use of ROPS and a seat belt is estimated "to be $99 \%$ effective in preventing death or serious injury in the event of a tractor rollover." 22 US data shows significant increases in the use of ROPS between 1993 and 2004, from $38 \%$ to $51 \% .{ }^{18,23}$

As Canadian agricultural machinery practices typically mirror those observed in the US, the observed decrease in fatal rollovers over our study period is almost certainly attributable to increased use of ROPS in Canadian agriculture settings. The observed decrease in fatalities also demonstrates the merits of engineered passive injury prevention strategies that require no change in behaviour on the part of the operator. Passive strategies are effective, and their utility is not specific to any particular demographic group defined by age, gender or geography. Our study findings point out a clear need for programs and policies that encourage the universal application of passive safety innovations in order to protect farm machinery operators from harm. In addition to the universal use of ROPS and seatbelts, ${ }^{22}$ these might include design innovations that (1) signal the operator when a machine is being operated at a dangerous angle or (2) make the practice of high hitching inconvenient if not impossible. Organizations involved in the development and promotion of such innovations are many; they include national safety associations (e.g. the Canadian Agricultural Safety Association), federal and provincial/territorial government departments and ministries (e.g. agriculture, labour, and the workers' safety and insurance boards), agricultural machinery manufacturers and institutions, health and safety coalitions, and coroners and medical examiners.

In conjunction with secondary injury prevention strategies such as ROPS, primary prevention programs (less efficacious than secondary prevention strategies) should focus on the most common causes of rollovers and educate operators about known operational hazards: side slopes and roadway ditches, especially during seasons where 
these are soft; steep inclines; dragging logs or implements; towing machines or extracting stumps or logs or machines stuck in fields.

The number of fatal rollover injuries we observed among children aged less than 10 years point to a need for different primary prevention strategies. Foremost of these is the need to limit young children's access to known occupational hazards on the farm, as described in a large existing case series. ${ }^{24}$ Young children typically do not possess the developmental abilities to recognize and react to dangerous occupational situations in an appropriate manner. ${ }^{25}$ It is also challenging for adults engaged in agricultural work to simultaneously supervise young children in the attentive, proximal and continuous manner that may be necessary to protect them from harm. ${ }^{25}$ The only truly effective solution for these rollover deaths is to prohibit young children from the agricultural worksite, including being on or in the vicinity of agricultural machinery.

\section{Strengths and limitations}

Our study was unique in that it examined the circumstances of rollovers in detail by mechanism. We made use of a robust dataset of national fatality data to describe patterns that are representative of agricultural rollover injuries in Canada. Our study also had its limitations. First, our analyses were restricted by the circumstance information recorded by the provincial abstractors, who in turn were limited by the information recorded on coroners' investigation reports, police reports, and occupational safety and health agency investigation reports. We were particularly limited in the information about the victim and the rollover circumstances such as whether the victim was a full-time or part-time worker, the type of farm production where the injury occurred, and whether safety equipment (ROPS or seatbelts) was on the machine and/or in use. Second, as fatality information was not available from Quebec in 2004-05, counts of fatalities for these later years of surveillance represent slight underestimates of expected national totals. The observed decline in the occurrence of rollover fatalities from 1990 to 2005 should also be interpreted with caution, although the patterns of injury are most likely to be representative.

\section{Summary}

Machine rollovers are one of the most common, yet preventable, causes of fatal agricultural injury in Canada. Our study identified the groups most at risk for sideways and backwards rollovers, and we documented the most common circumstances that led to these rollovers. By adhering to recommendations on ROPS and through understanding the circumstances in which these events most often occur, a substantial number of rollover fatalities could be avoided.

\section{Acknowledgements}

This work was funded by the Canadian Agricultural Safety Association.

The Canadian Agricultural Injury Surveillance Program (CAISP) was initiated in 1995. Collaborators representing each of Canada's ten provinces have been integral to the data collection activities that formed the basis of the data presented here. As of 2010, CAISP has a new name: the Canadian Agricultural Injury Reporting program (CAIR). It is now managed by the Alberta Centre for Injury Control and Research. CAIR is funded and supported by a grant from the Canadian Agricultural Safety Association, and Agriculture and Agri-Food Canada. These groups were not involved in the study design, data collection, analysis, interpretation of data, or the writing of and decision to submit the paper for publication.

\section{References}

1. Pickett W, Hartling L, Brison RJ, Guernsey JR. Fatal work-related farm injuries in Canada, 1991-1995. Canadian Agricultural Injury Surveillance Program. CMAJ. 1999;160:1843-8.

2. Franklin RC, Mitchell RJ, Driscoll TR, Fragar LJ. Agricultural work-related fatalities in Australia, 1989-1992. J Agric Saf Health. 2001;7:213-27.

3. Hard DL, Myers JR, Gerberich SG. Traumatic injuries in agriculture. J Agric Saf Health. 2002;8:51-65.

4. Pickett W, Hartling L, Dimich-Ward H, Guernsey JR, Hagel L, Voaklander DC, et al. Surveillance of hospitalized farm injuries in Canada. Inj Prev. 2001;7:123-28.
5. Hathaway LR, Riney LA, editors. Fundamentals of machine operation: agricultural safety. Moline (IL): Deere \& Company Service Training; 1987.

6. Centers for Disease Control and Prevention. Public health focus: effectiveness of rollover protective structures for preventing injuries associated with agricultural tractors. MMWR. 1993;42:57-9.

7. Centers for Disease Control and Prevention. Fatalities associated with improper hitching to farm tractors-New York, 1991-1995. MMWR. 1996; 45:307-11.

8. Springfeldt B, Thorson J, Lee BC. Sweden's thirty-year experience with tractor rollovers. J Agric Saf Health. 1998;4:173-80.

9. Conroy C, Fowler J. The Haddon matrix: applying an epidemiologic research tool as a framework for death investigation. Am J Forensic Med Pathol. 2000;21:339-42.

10. Statistics Canada. 2006 Census of agriculture [Internet]. Ottawa (ON): Statistics Canada; [modified 2009 Oct 5; accessed 2010 Dec 30]. Available from: http://www.statcan .gc.ca/ca-ra2006/index-eng.htm

11. Locker AR, Pickett W, Hartling L, Dorland JL. Agricultural machinery injuries in Ontario, 1985-1996: a comparison of males and females. J Agric Saf Health. 2002;8:215-23.

12. Rissanen P, Taattola K. Fatal injuries in Finnish agriculture, 1988-2000. J Agric Saf Health. 2003; 9:319-26.

13. Myers JR, Hendricks KJ. Agricultural tractor overturn deaths: assessment of trends and risk factors. Am J Ind Med. 2009;53:662-72.

14. Horsburgh S, Feyer A-M, Langley JD. Fatal work related injuries in agricultural production and services to agriculture sectors of New Zealand, 1985-94. Occup Environ Med. 2001; 58:489-95.

15. Myers JR, Hard DL. Work-related fatalities in the agricultural production and services sectors, 1980-1989. Am J Ind Med. 1995;27:51-63. 
16. Soloman C. Accidental injuries in agriculture in the UK. Occup Med. 2002; 52:461-6.

17. Voaklander DC, Hartling L, Pickett W, Dimich-Ward H, Brison RJ. Work-related mortality among older farmers in Canada. Can Fam Physician. 1999; 45:2903-10.

18. Loringer KA, Myers JR. Tracking the prevalence of rollover protective structures on U.S. farm tractors: 1993, 2001, and 2004. J Safety Res. 2008;39:509-17.

19. May JJ, Sorensen JA, Burdick PA, EarleRichardson GB, Jenkins PL. Rollover protection on New York tractors and farmers' readiness for change. J Agric Saf Health. 2006;12:199-213.

20. Sanderson WT, Madsen MD, Rautiainen R, Kelly KM, Zwerling C, Taylor CD, et al. Tractor overturn concerns in Iowa: perspectives from the Keokuk county rural health study. J Agric Saf Health. 2006;12:71-81.

21. Wilkins JR III, Engelhardt HL, Bean TL, Byers MV, Crawford JM. Prevalence of ROPS-equipped tractors and farm/ farmer characteristics. J Agric Saf Health. 2003;9:107-18.

22. Murphy DJ, Buckmaster DR. Rollover protection for farm tractor operators [Internet]. Pennsylvania State University (PA): Agricultural and Biological Engineering; 2003 [cited 2010 Dec 14.] Available from: http://www.abe.psu.edu/extension/ factsheets/e/E42.pdf

23. Myers JR, Snyder K. Roll-over protective structure use and cost of retrofitting tractors in the United States, 1993. J Agric Saf Health. 1995;1:185-97.

24. Brison RJ, Pickett W, Berg R, Linneman J, Zentner J, Marlenga B. Fatal agricultural injuries in preschool children: risks, injury patterns and strategies for prevention. CMAJ. 2006;174:1723-6.

25. Morrongiello B, Pickett W, Berg R, Linneman J, Brison RJ, Marlenga BL. Adult supervision and pediatric injuries in the agricultural worksite. Accid Anal Prev. 2008; 40:1149-56 